\title{
Chylothorax after high translumbar aortography
}

\author{
M.E.T. McMurdo
}

University Department of Medicine, Ninewells Hospital and Medical School, Dundee DD1 9SY, Scotland, UK.

\author{
Summary: Chylothorax is a rare complication of high translumbar aortography and a case is \\ described here.
}

\section{Introduction}

High translumbar aortography is an investigative procedure undertaken in patients with peripheral vascular disease to demonstrate the lower abdominal aorta, the pelvic and lower limb vessels. It is indicated where the femoral approach is precluded by arterial disease.

A case is reported here of a patient who sustained a chylothorax as a result of such a procedure.

\section{Case report}

A 74 year old woman was admitted for the investigation of peripheral vascular disease. Her activities were severely limited by intermittent claudication of the left leg on walking 15 yards. In an effort to establish the extent of her lower limb vascular disease, a high translumbar aortogram was attempted by an experienced radiologist. The aorta, however, could not be entered and the patient was allowed home the following day with an appointment to return in one month for the procedure to be repeated. Twenty-four hours after discharge she was referred to hospital by her general practitioner with dyspnoea and right sided chest pain. A chest X-ray confirmed the clinical impression of a pleural effusion. A diagnostic and therapeutic aspiration was performed and one litre of opaque milky white fluid was removed.

A diagnosis of traumatic chylothorax secondary to failed high translumbar aortography was made. Due to reaccumulation of the effusion, a further one litre of chyle was removed 48 hours later. At this stage the patient was commenced on a low fat, high protein diet in an attempt to keep chyle production to a minimum. Four days after admission the patient was well and remained so until her discharge one week later, with

Correspondence: M.E.T. McMurdo M.B., Ch.B., M.R.C.P. Accepted: 30 July 1986 neither clinical nor radiological evidence of reaccumulation of pleural effusion. Six weeks later translumbar aortography was performed without complication and she proceeded later to have an aortofemoral bypass graft with good result.

\section{Discussion}

Chylothorax is a rare complication of translumbar aortography first described in 1955 by Maluf \& McCoy, ${ }^{1}$ with a reported incidence of between 0.15 and 9 per thousand cases. ${ }^{2,3}$

High translumbar aortography is performed by inserting the needle $5 \mathrm{~cm}$ to the left of the midline posteriorly, passing directly under the twelfth rib and angled upwards and medially at an angle of 45 degrees until aortic pulsation is felt. The commonest cause of puncture of the thoracic duct is insertion of the needle too far laterally, permitting the needle to pass between the aorta and a vertebra, thus endangering several structures including the thoracic duct, the azygous vein, the right pleural cavity and the right lung. Obese patients present a particular hazard, as the needle has to be placed more laterally than usual to compensate for the fatty layer.

A total of 19 cases have been described in the literature, of which 12 were successfully treated conservatively by continuous tubal drainage of the effusion, accompanied by a low fat diet, and/or intravenous feeding. The crucial decision in the management of such cases is for how long to persist with the trial of conservative treatment, as spontaneous closure of a thoracic duct lymph fistula is unpredictable. ${ }^{4}$ In general, surgical correction of the fistula should be considered if: (1) loss of chyle in an adult exceeds $500 \mathrm{ml}$ per day; (2) flow of chyle persists for 
more than 14 days; (3) severe metabolic complications develop as a result of the chylous losses. ${ }^{5}$

The diagnosis of chylothorax depends on the recognition of chyle once it has been aspirated from the chest, and a lymphangiogram may be helpful in determining the site of the chyle leakage. ${ }^{6}$ There may be a latent period of, on average, 3 days $^{4}$ between the time of injury and the onset of the effusion, as chyle accumulates in the posterior mediastinum and eventually ruptures through the mediastinal pleura.

Less than 25 years ago the mortality associated with chylothorax and persistent thoracic duct-pleural fistula was high as a result of deaths from high calorie and protein losses. New techniques in nutritional support in the last decade have made non-operative

\section{References}

1. Maluf, N.S.R. \& McCoy, C.B. Translumbar aortography as a diagnostic procedure in urology. Am $J$ Roentgenol 1955, 73: 533.

2. McAfee, J.G. A survey of complications of abdominal aortography. Radiology 1957, 68: 825.

3. Pouliot, P., Levesque, M. \& Blery, M. Les chylothorax compliquant les aortographies directes. Ann Radiol 1971, 17: $543-548$. management effective in the majority of cases. Although it is a rare complication of translumbar aortography, it merits early recognition and appropriate treatment if life-threatening metabolic complications are to be avoided.

This case report emphasizes that, whenever possible, the transfemoral approach is to be preferred to translumbar aortography.

\section{Acknowledgements}

Thanks to Dr D. Emslie-Smith for his permission to report this case and thanks to Dr R.N. Johnston for his advice on the management of the patient.

4. Robinson, C.L.N. The management of chylothorax. Ann Thorac Surg 1985, 39: 90-95.

5. Teba, L., Dedhia, H.V., Bowen, R. \& Alexander, J. 윽 Chylothorax Review. Crit Care Med 1985, 13: 49-52.

6. Roy, P.H., Carr, D.T. \& Payne, W.S. The problem of chylothorax. Proc Mayo Clin 1967, 42: 457. 